\title{
Analysis on the Influence of Enterprise Micro-blog Interaction on Product Diffusion
}

\author{
Xue Mairan \\ School of Management, Wuhan University of Technology, Wuhan, P.R.China, 430070 \\ (E-mail:694758130@qq.com)
}

\begin{abstract}
As an enterprise marketing platform, micro-blog has been widely used. With its influence and number of users rapidly increasing, the commercial value has been reflected gradually. The article took sales of intelligent mobile phones as the review indicator of product diffusion, and selected official micro-blogs of Apple, Samsung, Miui, Lenovo mobiles as cases. Blogs from April, 2013 to March, 2014 were analyzed to research on impact of corporate official micro-blog interaction on product diffusion, based on the establishment of multiple linear regression model with dummy variables.
\end{abstract}

Key words: Corporate Official Micro-blog; Micro-blog Interaction; Product Diffusion

\section{Introduction}

After entering the Web2.0 era, new media are emerging constantly. As today's social hot word "micro-blog", it is undoubtedly the most frequently used new media. Based on the users' relationship, micro-blog is used to obtain, spread and share information, which is more convenient and rapid than the traditional blog. Information can be released and achieved via a computer or mobile phone in a timely manner. Twitter founder Dorsey said in 2007: "with 140 characters to change the world". In China, Meng Bo, Sina micro-blog head, also said that micro-blog is a change in the way of information dissemination. As Chinese micro-blogging platform representative, Sina micro-blog has had 2.5 billion users in two years, and its development speed is quite surprising.

In the marketing world, micro-blog has increasingly been favored by various types of enterprises. On the one hand, the external environment of harsh competition has forced the enterprises to focus on the product itself, and at the same time to highlight corporate image maintaining and popularizing; on the other hand, market competition requires advertising marketers to create new ways of marketing besides the existing way of marketing. The very popular micro-blog just fits the needs of enterprises, attracting a large number of enterprises to join the interaction with micro-blog users. On Sina micro-blog platform, for example, there had been only about 5,000 registered enterprise micro-blog users till October 2011, but the number rose to more than 16,000, fields covering catering, automobile, finance, fast consumption, etc.

The rising of micro-blog has been accompanied by the prosperity of micro-blog studies. Some enterprises have used micro-blog to carry interaction which has proved a big success, and therefore sparked academic attention of micro-blog business value. However, due to a relatively late research, there are just a few achievements with limited domain, and a universally recognized and widely applied theoretical system has not been formed. Any problems in practice still need to be further explored and verified. This paper will try an analysis on the influence of the micro-blog interaction on product diffusion.

\section{Research variables and data samples}

In twenty-first century, with the rapid development of science and technology, because product innovation is speeding, and consumer preferences vary greatly as well, product life cycle has been shortened, which has become an inevitable trend. This kind of performance is more obvious among electronic products such as mobile phones, laptops, digital cameras and other electronic products. The period of new product launch to withdraw from the market last only a short time, or even months. This kind of products is indispensable and important in our daily life with more contact with. What' $\mathrm{s}$ more, these products are often faced with the issue of new product diffusion. 
The article selected best seller official micro-blogs of Apple, Samsung, Miui, Lenovo mobiles as cases. Blogs from April, 2013 to March, 2014 were analyzed per quarter to count micro-blog quantity, praising quantity, forwarding quantity and reviewing quantity. And based on data from the relevant research institutions released quarterly, sales data of mobile phone per quarter can be estimated.

Product diffusion of the dependent variable takes mobile phone sales per quarter as the evaluation index obtained through the relevant research institutions data; based on previous studies, the main explanatory variables are micro-blog interaction, which will be evaluated through micro-blog quantity, praising quantity, forwarding quantity and reviewing quantity. And the following hypotheses are put forward:

H1: There is a positive correlation between micro-blog released quantity and product sales.

$\mathrm{H} 2$ : There is a positive correlation between micro-blog total praising quantity and product sales.

H3: There is a positive correlation between micro-blog total forwarding quantity and product sales.

H4: There is a positive correlation between micro-blog total reviewing quantity and product sales.

\section{Empirical analysis}

Through multiple regression analysis of statistics data, the results are presented in Table 1.

Table 1 Regression results of micro-blog, praising, forwarding, reviewing and sales amount

\begin{tabular}{c|c|c|c}
\hline $\begin{array}{c}\text { Dependent } \\
\text { Variable }\end{array}$ & \multicolumn{2}{|c}{ Total Sales Amount Quarterly } \\
\hline $\begin{array}{c}\text { Independent } \\
\text { Variable }\end{array}$ & Coefficient & P Value \\
\hline $\begin{array}{c}\text { C Constant } \\
\text { Term) }\end{array}$ & $1.037 \mathrm{E} 7$ & 6.872 & .008 \\
\hline $\begin{array}{c}\text { Micro-blog } \\
\text { Quantity } \\
\text { quantity }\end{array}$ & -471.410 & -3.707 & .944 \\
\hline $\begin{array}{c}\text { Total Praising } \\
\text { Quantity }\end{array}$ & $-161.303^{* * *}$ & 2.306 & .007 \\
\hline $\begin{array}{c}\text { Total Forwarding } \\
\text { Q }\end{array}$ & $4.462^{*}$ & 2.454 & .055 \\
\hline Total Reviewing & $1.323^{*}$ & 2.130 & .057 \\
\hline R Sqantity & 0.731 & & \\
\hline
\end{tabular}

Note: $* * *, * *, *$ means significant in level $1 \%, 5 \%, 10 \%$.

According to the results of the table, there is no significant positive correlation between micro-blog quantity and mobile phone sales $(\mathrm{p}=0.944>0.1)$. So it can be concluded that the Hypothesis 1 is invalid, because enterprise released micro-blog quantity does not significantly affect mobile phone sales amount. Therefore, we exclude the independent variable---micro-blog quantity, and try the regression analysis of praising, forwarding, reviewing and sales amount to build a measurement model.(in Table 2) 
Table 2 The regression results of praising, forwarding, reviewing and sales volume

\begin{tabular}{c|c|c|c}
\hline $\begin{array}{c}\text { Dependent } \\
\text { Variable }\end{array}$ & \multicolumn{3}{|c}{ Total Sales Amount Quarterly } \\
\hline $\begin{array}{c}\text { Independent } \\
\text { Variable }\end{array}$ & Coefficient & T Value & P Value \\
\hline $\begin{array}{c}\text { C (Constant } \\
\text { Term) }\end{array}$ & $1.017 \mathrm{E} 7$ & 3.200 & .000 \\
\hline $\begin{array}{c}\text { Micro-blog } \\
\text { Quantity }\end{array}$ & $-162.444^{* * *}$ & -3.332 & .003 \\
\hline $\begin{array}{c}\text { Total Forwarding } \\
\text { Quantity }\end{array}$ & $4.423^{* *}$ & 2.150 & .030 \\
\hline $\begin{array}{c}\text { Total Reviewing } \\
\text { Quantity }\end{array}$ & $1.341^{* *}$ & 2.130 & \\
\hline R & 0.731 & & \\
\hline R Square & 0.535 & & \\
\hline Prob.(F-statistic) & 0.023 & & \\
Note: $* * * * * *$ means significant in level $1 \%, 5 \%, 10 \%$. &
\end{tabular}

According to Table 2, the regression results showed that all of the above variables were tested, $\mathrm{R}$ and $\mathrm{R}$ square values were acceptable, $\mathrm{F}$ statistic was tested to be significant in the 5\% level. Overall, the total forwarding quantity has the closest positive correlation with sales amount, the next, the total reviewing quantity. The total praising quantity displayed a negative correlation. The conclusion can be drown that Hypotheses $3 \& 4$ are valid and Hypothesis 2 is invalid.

\section{Conclusion and Prospects}

In this paper, through empirical analysis on the enterprise official micro interaction effect on the product diffusion, and a measurement model has been built about micro-blog quantity, praising quantity, forwarding quantity, reviewing quantity and sales amount. The findings are as follows: (1) the impact of micro-blog quantity of products on product diffusion is not significant, so it is more important to enhance micro-blog quality and eye-catching points to increase result-targeted user interaction; (2) the total praising quantity has a negative impact on product sales, which is contrary to previous hypothesis All statistical data were collected regardless of contents, and there seems to be a relation between praising quantity and contents which is not included in the research. In addition, compared with micro-blog forwarding quantity and micro-blog reviewing quantity, micro-blog praising quantity is relatively less, which may have an negative impact on the results. Therefore, the impact of micro-blog praising quantity needs to be further explored and validated in the following research. (3) the total forwarding quantity and reviewing quantity have a positive impact on sales amount which suggests that future micro-blogs should meet the needs and taste of users to facilitate active participation with more forwarding and reviewing, which finally helps product diffusion.

\section{References}

[1] ZHANG Yonggang. An empirical study on the marketing effect of micro-blog based on the user interaction model --- a case study of the hotel industry[J]. Travel Research, 2013, 04: 78-83

[2] Chris Murdough. Social media measurement: It' s not impossible[J]. Journal of Interactive Advertising, 2009(10): 94-95

[3] TANG Xingtong. The trend of social media marketing: strategies and methods[M]. Tsinghua University Press, 2011: 119-124

[4] JIN Yongsheng, WANG Rui, CHEN Xiangbin. A short-term interactive model of the marketing effect and the number of fans in micro-blog[J]. Management Science, 2011, 04: 71-83

[5] CHENG Xuefen. Research on influence factors and measurement of enterprise' s marketing effect of micro-blog[D]. Dalian University of Technology, 2012 
[6] BI Lingyan, ZHANG Zhenpeng, Zuo Wenming. The evaluation model and empirical study of micro-blog effect based on the micro-blog communication information flow[J]. Intelligence Journal, 2013, 32(7): 69-73

[7] ZHU Yin. Research on diffusion and intervention mechanism of ICT products[D]. Shanghai Jiao Tong University, 2009

[8] HU Zuohao, HUANG Feihua, ZHAO Ping, WANG Yong. The impact of advertising on the diffusion of new products: a case study of mobile phone products[A]. Management Science in China, 2007, 15(z1): 529-531

[9] Sebatiano Alessio Delre. Effects of social Networks on Innovation Diffusion and Market Dynamics, 2007 